\title{
IDENTIFICATION OF MATHEMATICAL MODEL OF WATER LINE IN HEAT EXCHANGERS
}

\section{${ }^{1}$ Igor Nunes Lopes, ${ }^{1}$ Livia da Silva Oliveira, ${ }^{1}$ Jean Mark Lobo de Oliveira, ${ }^{1}$ Fábio Peso da Cruz and ${ }^{* 2}$ David Barbosa de Alencar}

\author{
${ }^{1}$ Academic Department, University Center FAMETRO, Manaus-AM, Brazil \\ 2Research Department, Institute of Technology and Education Galileo of Amazon (ITEGAM), Brazil
}

\section{ARTICLE INFO}

\section{Article History:}

Received $19^{\text {th }}$ December, 2019

Received in revised form

$21^{\text {st }}$ January, 2020

Accepted $17^{\text {th }}$ February, 2020

Published online $31^{\text {st }}$ March, 2020

Key Words:

Heat exchanger; Cold fluid; Estimated

mathematical model; Computational simulation.

*Corresponding author:

David Barbosa de Alencar

\begin{abstract}
Heat exchangers are widely used in industries for the use of thermal energy generated from different processes. For a definite use of this energy, the temperatures of the hot and cold fluids passing through the heat exchanger must be monitored and controlled efficiently. A suitable model of the heat exchanger is required for monitoring and control purposes. The objective of this work is to mathematically model a heat exchanger using a system identification method using a computational tool. The methodology used consists of data collection and simulation of models, as well as the analysis of comparison of the estimated models with the real system. The results show that the identification through computational simulation presented satisfactory results.
\end{abstract}

Copyright (C) 2020, Igor Nunes Lopes et al. This is an open access article distributed under the Creative Commons Attribution License, which permits unrestricted use, distribution, and reproduction in any medium, provided the original work is properly cited.

Citation: Igor Nunes Lopes, Livia da Silva Oliveira et al. 2020. "Identification of mathematical model of water line in heat exchangers", International Journal of Development Research, 10, (03), 34619-34622.

\section{INTRODUCTION}

Heat transfer equipment is an integral part of industries that employ thermal exchange processes, the purpose of which is to cool or heat a certain fluid. They need to use energy inputs efficiently in order to avoid high costs resulting from losses. Temperature control is crucial for the effective use of a heat exchanger [1]. They are widely used in heaters, air conditioners, power generation plants, chemical, petrochemical, medicine and food plants, among other applications [2]. Therefore, the control of this device is necessary depending on the complexity of the process in which they are involved. The first step in the analysis and design of a control system is to define the mathematical model of the plant under consideration. Obtaining the mathematical model of the dynamics of a system can be very complex, leaving the experimental method as a practical and viable alternative [2]. In this article we will use the System Identification Toolbox, present in Matlab®., As a computational tool to identify the transfer function that most closely matches the dynamics of the cold water line of the heat exchanger. This tool allows the analysis of collected data and the estimation of mathematical models of plants. The designer is responsible for interpreting the results in order to use the best model for each type of system.

\section{Bibliographic Review}

Nowadays, improving the efficiency of industrial processes is considered to be one of the most significant challenges for both control engineering and process engineering. Many possibilities for achieving this goal have been presented suggesting the concepts of such improvements. Some of them deal with the economic impact of improved control. Bauer and Craig [3] presented a survey of the methods used to assess the economic justification for applying new advanced process control systems to a process. Some of these methods are based on performance functions that incorporate economic aspects of variations in process variables around optimal operating points. In industrial heat exchange systems, heat exchangers play an important role and their modeling is crucial both to optimize design and operation, in addition to costs. Different heat exchangers are applied in the industry, among which we highlight the types [4]: 
Hull and tube: A set of these tubes contains the fluid that must be heated or cooled. The second fluid flows over the tubes being heated or cooled so that it can provide the heat or absorb the heat needed for a specific process. They are mostcommonlyused in industry;

Plates: One is made up of multiple, thin, slightly separated plates that have very large surface areas and heat transfer fluid flow passages. This stacked plate arrangement can be more effective, in a given space, than the hull and tube heat exchanger;

Finned plates: This type of heat exchanger uses fluid passages in interleaved plates to increase the effectiveness of the unit. The designs include cross flow and counter flow with several fin configurations such as straight fins, offset fins and wavy fins.

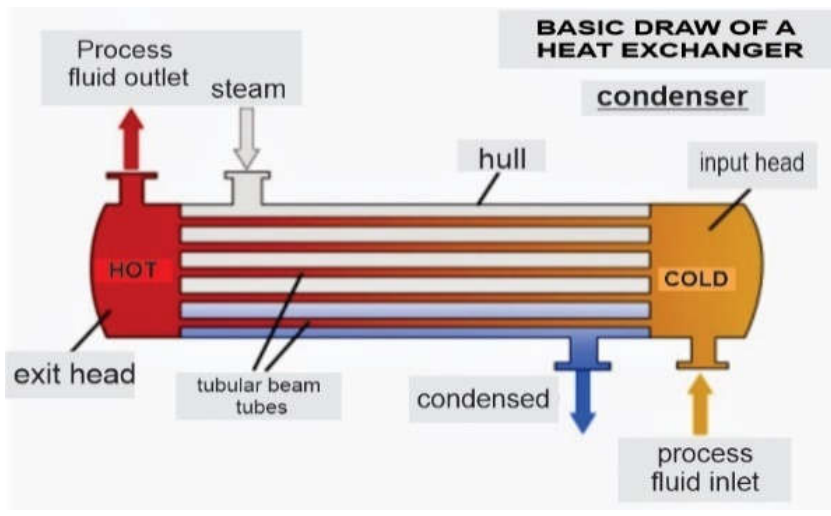

Figure 1. Basic diagram of a shell and tube heat exchanger

In this study, the model obtained does not incorporate the influence of measured disturbances and does not describe the internal couplings between the process inputs and outputs. Simplified modeling is necessary, one possibility is to apply the simplified dynamic description in the form of the transfer functions of Laplace FOPDT (First Order Plus Dead Time), whose parameters can be easily identified from the response to the process step. This approach is very popular to approximate the significant dynamic properties of SISO (Single Input Single Output) industrial processes [5]. The number of model parameters must be minimized and the reliable method for identifying their values must be ensured based only on measurement data collected from a specific system. A heat exchanger system presents the flow of liquid in cold and hot temperatures as inputs. After the heat exchanges that occur in the thermal process, cold and hot fluids at new temperatures are produced. The scheme presented in figure 2 presents the object of study of this research, where only the thermal model of the cold water line will be identified.

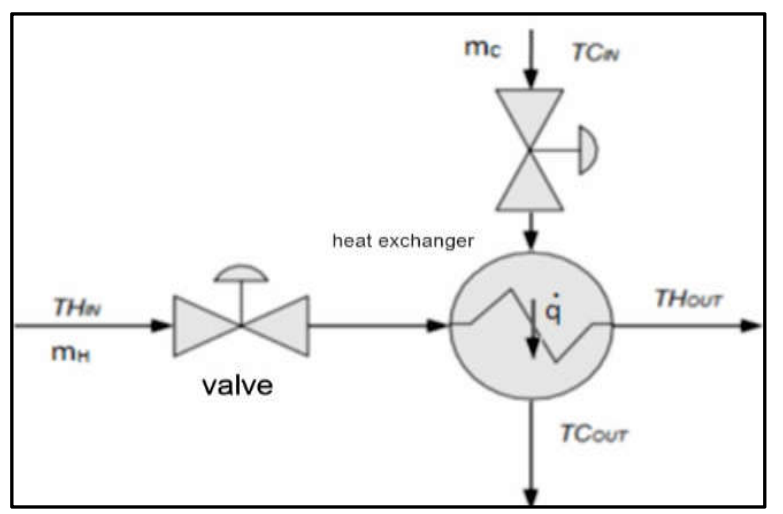

Figure 2. Heatexchanger system
For [6], heat transfer in a exchanger usually involves convection in each fluid and conduction through the wall that separates the two fluids. In the analysis of heat exchangers, it is convenient to work with the global heat transfer coefficient $\mathrm{U}$, which represents the contribution of all these effects on heat transfer. The rate of heat transfer between the two fluids at one location of a heat exchanger depends on the magnitude of the temperature difference at the location, which varies across the heat exchanger [7].

The fundamental equation for heat exchangers is given by equation (1):

$Q=U \cdot A_{T C} \cdot \Delta T_{m l}$

Where:

$\mathbf{Q}$ is the heat transfer rate $(\mathrm{w})$;

$\mathbf{A}_{\text {TC }}$ is the heat exchange area $\left(\mathrm{m}^{2}\right)$;

$\mathbf{U}$ is the global heat transfer coefficient $\left(\mathrm{w} / \mathrm{m}^{2 \circ} \mathrm{C}\right)$;

$\Delta \mathbf{T}_{\mathrm{ml}}$ is the average temperature difference between fluids.

Assuming also that the heat transfer of the exchanger fluids and the neighborhood are negligible and that phase changes of the fluids occur, it is possible to reach the heat transfer rates of the hot and cold fluids, respectively, according to the equations (2) and (3) [7]:

$q=m_{H} C_{p H}\left(T H_{I N}-T H_{O U T}\right)$

$q=m_{C} C_{p C}\left(T C_{I N}-T C_{O U T}\right)$

Where:

$\mathbf{m}_{\mathbf{H}}$ is the mass flow rate of the hot fluid;

$\mathbf{C}_{\mathrm{pH}}$ is the specific heat at constant pressure of the hot fluid (W $\left./{ }^{\circ} \mathrm{C}\right)$;

(TH $_{\text {IN }}$ and $\left.\mathbf{T H}_{\text {OUT }}\right)$ are, respectively, the inlet and outlet temperatures for the hot fluid $\left({ }^{\circ} \mathrm{C}\right)$;

$\mathbf{m}_{\mathbf{C}}$ is the mass flow of the cold fluid $(\mathrm{kg} / \mathrm{s})$;

$\mathbf{C}_{\mathbf{p C}}$ is the specific heat at constant pressure of the cold fluid $\left(\mathrm{W} /{ }^{\circ} \mathrm{C}\right)$;

( $\mathbf{T C}_{\mathbf{I N}}$ and $\mathbf{T} \mathbf{C}_{\text {OUT }}$ ) are the cold fluid inlet and outlet temperatures $\left({ }^{\circ} \mathrm{C}\right)$, respectively.

The rate of heat transfer in the tubes is given by:

$\dot{q}=U \cdot A_{T C}\left(T C_{O U T}-T H_{O U T}\right)$

Applying the principle of energy conservation to the elements, we have that:

$w C_{p H} \frac{d T H_{O U T}}{d t}=m_{H} C_{p H}\left(T H_{I N}-T H_{O U T}\right)+\dot{q}=$
$m_{H} C_{p H}\left(T H_{I N}-T H_{O U T}\right)+U A_{T C}\left(T C_{O U T}-T H_{O U T}\right)$

(4)

\section{MATERIALS AND METHODS}

The system illustrated in figure 2 allows the control of the hot fluid $\left(\mathrm{TH} \backslash_{\text {OUT }}\right.$ ) and cold $\left(\mathrm{TC}_{\mathrm{OUT}}\right)$ outlet temperatures by manipulating the net hot $\left(\mathrm{m}_{\mathrm{H}}\right)$ and cold $\left(\mathrm{m}_{\mathrm{C}}\right)$ fluid inlet rates. To determine the influence of the mass of hot fluid at the outlet of the exchanger, a step associated with a white noise at the inlet is applied. 


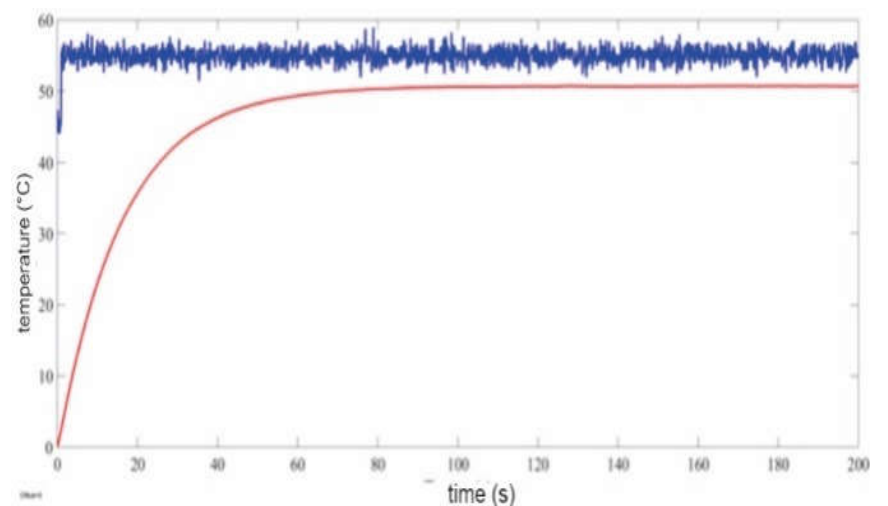

Figure 3. Input x Output of the hot fluid temperature

Table 1 shows the parameters used during the simulations, considering water as the fluid used.

Table 1. Parameters used

\begin{tabular}{lll}
\hline & Physical Construction and Operating Data in & Values \\
& Permanent Regime & \\
\hline$T C_{I N}$ & Cold water inlet temperature & $24^{\circ} \mathrm{C}$ \\
$T H_{I N}$ & Hot water inlet temperature & $45^{\circ} \mathrm{C}$ \\
$T C_{O U T}$ & Cold water outlet temperature & $27,2^{\circ} \mathrm{C}$ \\
$T H_{O U T}$ & Hot water outlet temperature & $50^{\circ} \mathrm{C}$ \\
$m_{C}$ & Cold water flow & $0,0251 / \mathrm{s}$ \\
$m_{H}$ & Hot water flow & $0,0261 / \mathrm{s}$ \\
$A_{T C}$ & Heat exchange area & $0,02 \mathrm{~m}^{2}$ \\
$U$ & Coef. Global heat exchange & $1000 \mathrm{w} / \mathrm{m}^{2} . \mathrm{K}$ \\
$C_{p C}, C_{p H}$ & Cold / hot liquid density & $1000 \mathrm{~kg} \cdot \mathrm{m}^{-3}$ \\
$\mathrm{n}$ & Specific cold / hot liquid heat & $4180 \mathrm{~J} / \mathrm{kg} \cdot \mathrm{K}$ \\
$V_{L}$ & Number of heat exchange cells & 50 \\
& Net volume supported by tubes & $0,0005 \mathrm{~m}^{3}$ \\
\hline
\end{tabular}

In order to perform the estimation of the mathematical model for the cold fluid inlet line, the data are collected experimentally. In possession of the input and output data, computational tools are used to identify Matlab ${ }^{\circledR}$ systems. The analysis of the hot water line will be disregarded, keeping it fixed on a step-type sign:

$T C_{I N}=24^{\circ} \mathrm{C}$

$T C_{\text {OUT }}=27,2^{\circ} \mathrm{C}$.

During the experiment, 563 values of $\mathrm{TC}_{\mathrm{OUT}}$ were collected for $\mathrm{TC}_{\mathrm{IN}}$ oscillations close to the desired setpoint, with sampling time of $1 \mathrm{~s}$, as shown in figure 4 .
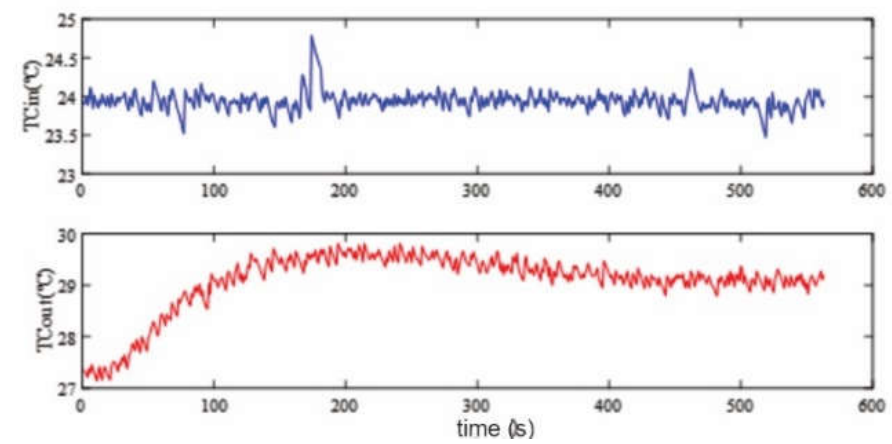

Figure 4. Inlet and outlet temperature $x$ cold water time

Half of the signal was used to estimate the model, in green from 0 to $281 \mathrm{~s}$ and the rest in red, from 282 to 563 , for model validation, as shown in Figures 5.
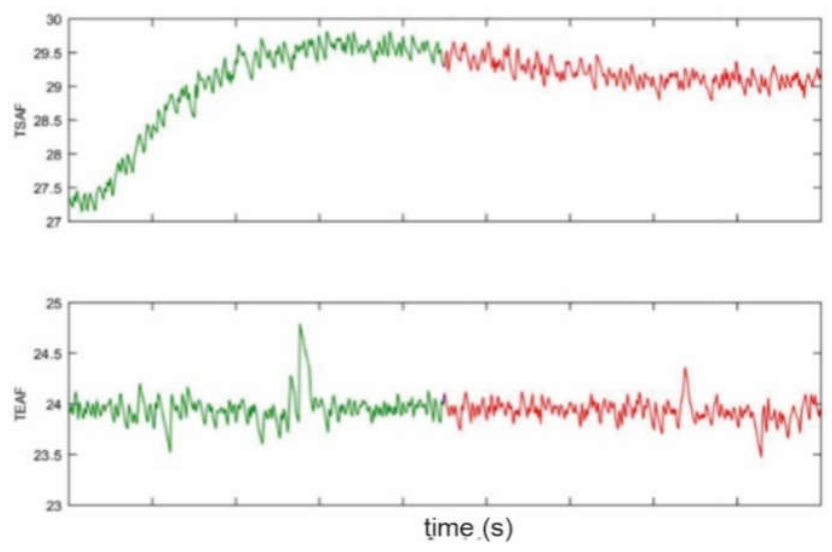

Figure 5. Sign used to estimate and validate the model

Three types of mathematical models were used to estimate the cold water line model of the heat exchanger system: Transfer functions, state space and non-linear models. The best fit was verified for each type of model. Below are the correspondence responses for each model. The transfer function method presents the best response in a third order model, with $82.32 \%$ approximation to the system model. Models above this order do not respond satisfactorily. The four best answers are illustrated in figure 6 and figure 7 shows the answer for the best model.

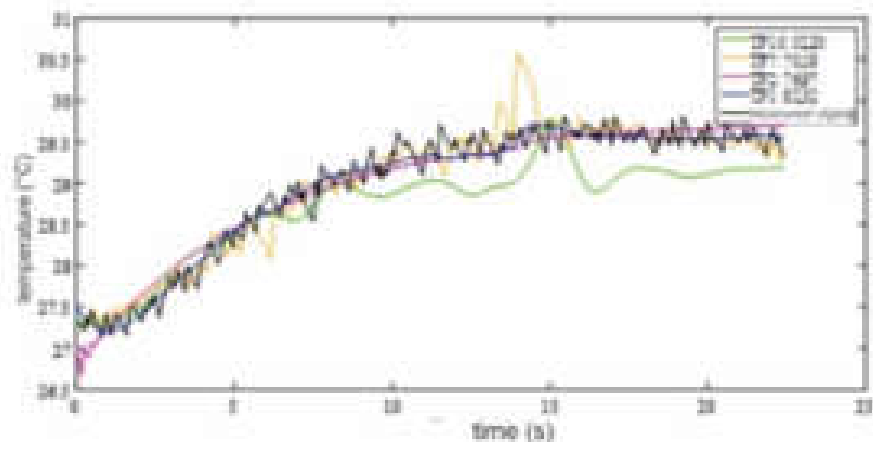

Figure 6. Response by the transfer function method

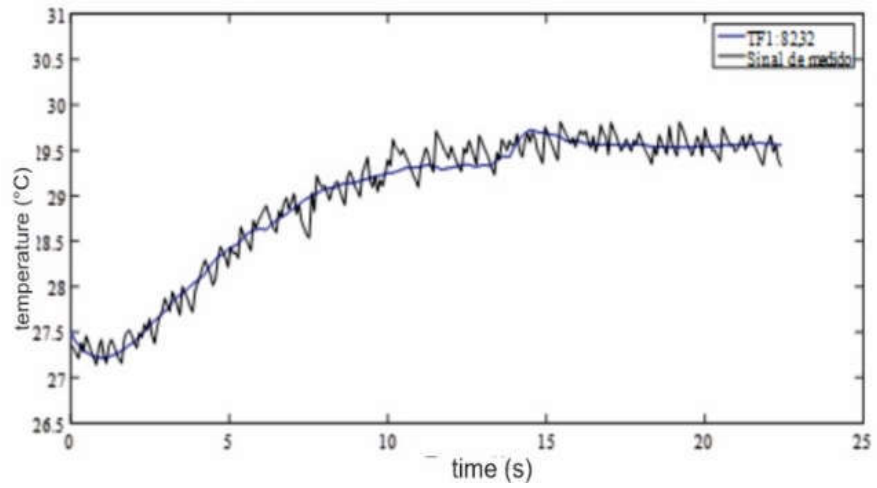

Figure 7. Response of the best validity model

In the state space method, the best result was $42.32 \%$ approximation, with an order one system, as shown in Figure 8.

\section{RESULTS AND DISCUSSIONS}

The best model obtained by the transfer function method is given by equation (5) 
$: \frac{T C_{O U T}}{T C_{I N}}=\frac{0,877 s+0,2487}{s^{2}+0,9786 s+0,2016}$

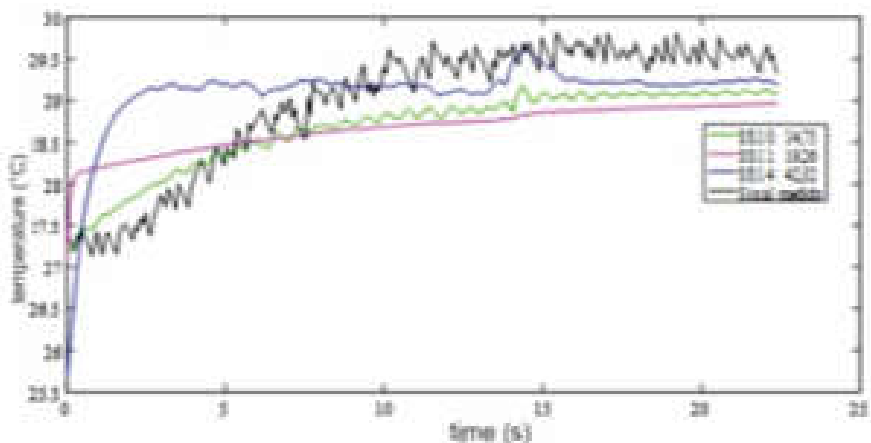

Figure 8. Validation response for the state space method

The state space model of the estimated model that came closest to the system and given by the system of equations in (6):

$\mathrm{dx} / \mathrm{dt}=\mathrm{Ax}(\mathrm{t})+\mathrm{Bu}(\mathrm{t})+\mathrm{Ke}(\mathrm{t})$

$y(t)=C x(t)+D u(t)+e(t)$

Where A, B, C and D are the following matrices:

$\mathrm{A}=\left[\begin{array}{ccccc}0.2927 & 2.577 & 9.979 & 2.522 & 4.247 \\ 2.597 & 14.28 & -48.47 & -11.32 & -19.8 \\ 3.1610 & 24.51 & -32.67 & -10.74 & -23.63 \\ 0.698 & 5.623 & -11.49 & -3.911 & 18.23 \\ 0.6327 & -7.378 & 20.73 & 16.35 & 8.678\end{array}\right]$

$\mathrm{B}=\left[\begin{array}{c}-0.7235 \\ 4.131 \\ 3.141 \\ 1.319 \\ -1.179\end{array}\right]$

$\mathrm{C}=\left[\begin{array}{lllll}2.102 & -1.304 & 0.1643 & -0.2118 & -0.2944\end{array}\right]$

$\mathrm{D}=[T C i n]$

Figure 9 shows the block diagram for simulation. The transfer function of the estimated model was inserted and compared with the impulse response for hot water.

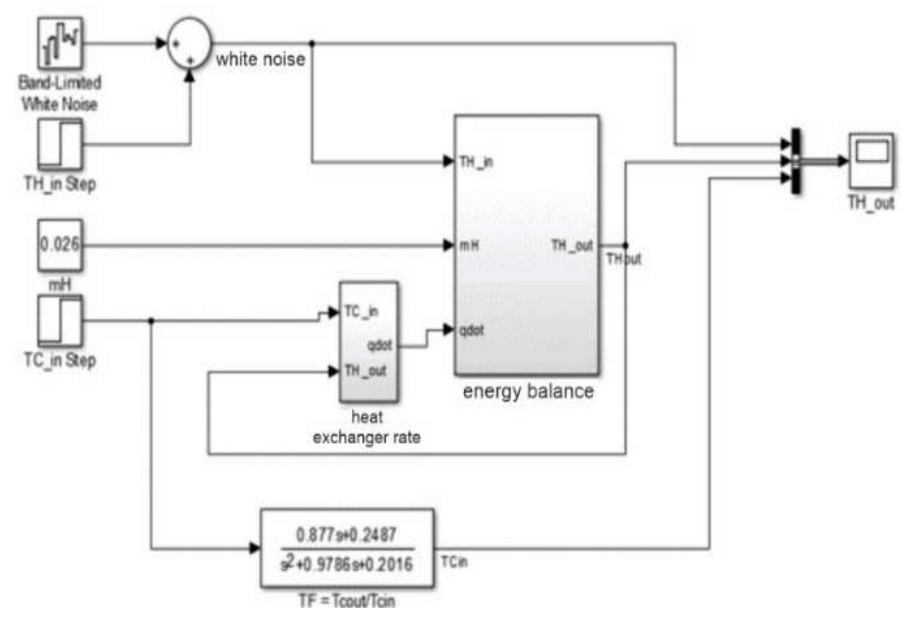

Figure 9. Block diagram for step response simulation

Figure 10 illustrates the comparative graph of the $\mathrm{TH}_{\text {out }}$ originally used in the mathematical model and $\mathrm{TC}_{\mathrm{out}}$ of the estimated model.

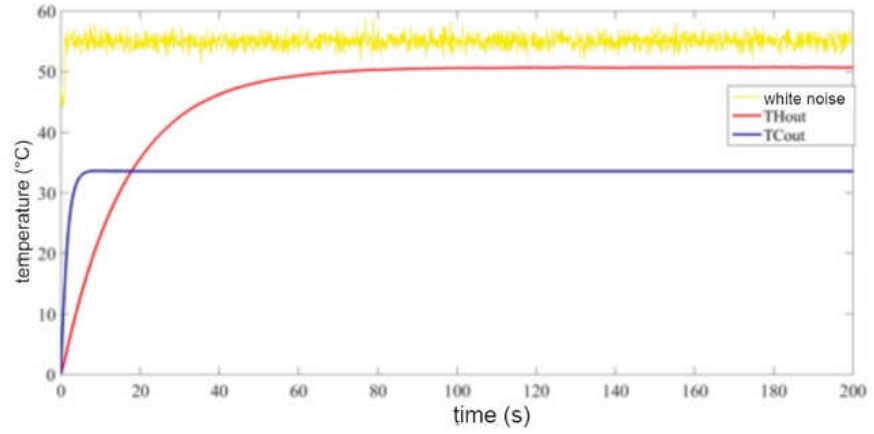

Figure 10. Graph of model response to a step signal

\section{Conclusion}

Estimating mathematical models of physical systems using computational tools starts with the collection of input and output signals from the object of study, followed by the treatment of signals, estimation of the model and finally, its validation, so that, at the end of this process we have a transfer function or a model in the state space that represents the dynamics of the system. In this article, we used the model estimation method represented by a transfer function and another by a model in the state space. After several tests to elevate the order of the system, it was found that the responses were satisfactory to some degree. Increasing the degree of the estimated models even more, the response tended to diverge more and more from the real system. The best results obtained were $82.32 \%$ for the third order transfer function method and $42.32 \%$ for the state space model.

\section{Acknowledgments}

To the Metropolitan Teaching Institute - IME, (University Center FAMETRO). To my parents, who despite all the difficulties, helped me in the realization of my dream. To my work friends and research partners, for all the help and support during this very important period of my academic training. To all the people who directly or indirectly contributed to my research.

\section{REFERENCES}

ÁlVAREZ, J. D.; YEBRA, L. J.; BERENGUEL, M. Repetitive control of tubular heat exchangers. JournalofProcessControl, v. 17, n. 9, p. 689701, 2007.

ÇENGEL, A. Y.; GHAJAR, A. J. Transferência de calor e massa. $4^{\circ}$ ed. Editora McGraw-Hill, 2012.

RAUL, Pramod R. et al. Comparison of model-based and conventional controllers on a pilot-scale heat exchanger. ISA transactions, v. 52, n. 3, p. 391-405, 2013.

SAHOO, A.; RADHAKRISHNAN, T. K.; RAO, C. Sankar. Modeling and control of a real-time shell and tube heat exchanger. Resource-Efficient Technologies, 2017.

SAUNDERS, Edward Alfred Donald. Heat exchangers: Selection, Design and Construction. New York: Longman Scientific and Technical. 1988.

Z. Yuan, B. Chen, G. Sin, R. Gani, State-of-the-art of progress in the optimization- based simultaneous design and control for chemical processes, AIChE J. 58 (6) (2012) 1640-1659. 